\title{
Design Optimization of Shell and Tube Heat Exchanger by Vibration Analysis
}

\author{
Shravan H. Gawande ${ }^{1}$, Appasaheb A. Keste ${ }^{1}$, Laxman G. Navale ${ }^{1}$, Milindkumar R. Nandgaonkar ${ }^{1}$, \\ Vaishali J. Sonawane ${ }^{1}$, Umesh B. Ubarhande ${ }^{2}$ \\ ${ }^{1}$ Department of Mechanical Engineering, Modern Education Society's College of Engineering, Pune, India \\ ${ }^{2}$ PEM Design (R\&D), Alfa Laval (India) Ltd., Pune, India \\ E-mail: shgawande@gmail.com \\ Received July 23, 2011; revised August 7, 2011; accepted August 15, 2011
}

\begin{abstract}
In this paper a simplified approach to optimize the design of Shell Tube Heat Exchanger [STHE] by flow induced vibration analysis [FVA] is presented. The vibration analysis of STHE helps in achieving optimization in design by prevention of tube failure caused due to flow induced vibration. The main reason for tube failure due to flow induced vibration is increased size of STHE. It is found that in case of increased size of STHE, the surface area and number of tubes increases, thus the understanding and analysis of vibration becomes a very difficult task. Again it is found that flow induced vibration analysis is considered as an integral part of mechanical \& thermal design of STHE. The detailed design, fabrication, testing and analysis work was carried out at Alfa Laval (India), Ltd., Pune-10.
\end{abstract}

Keywords: Heat Exchanger, Flow-Induced Vibration, TEMA, HTRI

\section{Introduction}

The principal culprit in flow induced vibration of tubes of STHE is the unsupported tube lengths subjected to large flow rates on shell side. The increased size of STHE due to large flow rates is responsible for vibration of tubes, which further leads to tube failure. Also the design of STHE is made safer by modifying shell type and/or baffles style and baffle design. Thus, the vibration analysis is of utmost importance in design of STHE. So, the flow induced vibration analysis is considered as an integral part of thermal design.

The characteristics of vortex shedding from tube banks with closely mounted serrated fin was investigated in [1] where the relationship between the Strouhal number defined by the equivalent diameter as the characteristic length of a finned tube in the tube banks and the Strouhal number map for bare-tube banks was examined. Whereas in [2] the author has presented various outlet conditions of a shell and tube heat exchanger theoretically and experimentally in which it is observed that prime parameter geometry of outlet affects the performance, maintenance and life span of a vertical shell and tube evaporator. The heat transfer enhancement has been achieved in [3], by modifying the configuration of a shell-and-tube heat ex- changer, through the installation of sealers in the shellside. The gaps between the baffle plates and shell is blocked by the sealers, which effectively decreases the short-circuit flow in the shell-side. The original shortcircuit flow then participates in heat transfer, which intensifies the heat transfer performance inside the heat exchanger. The use of a non-traditional optimization technique; called Particle Swarm Optimization (PSO), for design optimization of shell-and-tube heat exchangers from economic view point is explored in [4] in which minimization of total annual cost is considered as an objective function. Three design variables such as shell internal diameter, outer tube diameter and baffle spacing are considered for optimization. Two tube layouts viz. triangle and square are also considered for optimization. The results of optimization using PSO technique are compared with those obtained by using Genetic Algorithm (GA). Also the optimization of the design of shelland-tube heat exchangers by minimization of the thermal surface of the equipment, for certain minimum excess area and maximum pressure drops, considering discrete decision variables is presented in [5]. The heat transfer coefficient and pressure drop on the shell side of a shell-and-tube heat exchanger has been obtained experimentally in [6] for three different types of copper tubes. 
The comprehensive experimental investigation on the augmentation of heat transfer coefficients and pressure drop during condensation of HFC-134a in a horizontal tube at the presence of different twisted tape inserts was carried out in [7]. The experiments were performed for a plain tube and four tubes with twisted tapes inserts of 6 , 9, 12 and 15 twist ratios. Similarly, the numerical and experimental investigations to understand convective heat transfer from a single round pipe coiled in rectangular pattern are presented in [8] where the studied heat exchangers were composed with inner and outer coils so that the exterior flow is very similar to flow within tubebundles. The inner and outer coils of the heat exchangers are in turn composed of bends and straight portions. The investigation of the flow field and the heat transfer characteristics of a shell-and-tube heat exchanger for the cooling of syngas were carried out in [9] in which the finite volume method based on FLUENT software and the turbulence model was adopted for modeling turbulent flow. The pressure drop, the temperature distribution and the variation of local heat transfer were studied under the effects of the syngas components and the operating pressure, and the effect of the arrangement of the baffles on the heat transfer has been studied.

In this proposed work design, development \& testing of STHE is carried out. Along with the parameter considered in [1-8], vibration analysis is performed to optimized unsupported span of tube by using HTRI software. Detail overview on work carried out by researchers is presented in Section 1, Section 2 \& 3 states mechanics of flow-induced vibration and the current problem definition \& objective, details of STHE is given in Section 4 . Section 5 explores results of flow-induced vibration analysis, final investigations and results are presented in Section 6 and concluding remark is given in Section 7.

\section{Mechanics of Flow-Induced Vibration}

Failures of heat exchangers caused by flow-induced vibration are mainly in terms of the detriments of heat exchanger tubes. Generally, there are several main mechanisms for flow-induced vibration in heat exchangers as follows:

\subsection{Vortex Shedding}

When shell side fluid flows across heat exchanger tubes, alternately varying Karman's vortex streets will come into being downstream of tubes, which generates periodic changing exciting forces, which direction is perpendicular to fluid flow, and results in vibration of tubes. When frequency of vortex shedding is close or equal to the natural frequency of tube, violent vibration will occur.

\subsection{Fluid-Elastic Excitation}

When fluid flows across tube bundle, due to the complexity of flow condition, some certain tube in the bank may take instant movement, thereby the flow field around it changes and the equilibrium of forces on adjacent tubes is broken, which makes tubes move and begin vibrating. When flow rate increases to a certain degree, work of fluid elastic force on tube bundle will be larger than the work consumed by damping action of tubes, then amplitude of tube will increase rapidly and cause tubes to collide with each other and be destructed.

\subsection{Turbulent Buffeting}

Turbulence is generated when shell side fluid, flow through tube bundle. In the depth of in-line and interlacing arrangement of tube bundle, with irregular turbulence enlarging gradually, degree of turbulent pressure fluctuation augments and has heat exchange tubes endure random fluctuating acting forces. When basic frequency of turbulence pulsating is proximal or equal to natural frequency of tube, fierce vibration will take place.

\subsection{Fluid-Elastic Whirling}

This is characterized by tubes vibrating in an orbital or "whirling" manner, once sufficient energy is available for resonance to occur. This motion is produced when the shell side flows across the tubes causes both lift and drag movement of tubes at their natural frequencies. It can lead to a "runaway" condition if the energy supplied to tubes cannot be absorbed by the system damping and, thereby, lead to failure of tubes due to flow-induced vibration. Such a failure is likely to occur if the cross flow velocity is greater than a critical velocity.

\subsection{Acoustic Resonance}

Acoustic resonance occurs only on the condition that shell-side fluid is gas. When gas flows across tube bundle, acoustic standing waves, which is perpendicular to both tubes and flow direction, may come into being and be reflected repeatedly by inner wall of heat exchanger. Meanwhile, as gas flows across tube bundle, Karman's vortex street comes into being behind tubes. And when frequency of vortex street accords with the frequency of acoustic standing waves, the couple will come and all the kinetic energy of flow media will be transmuted to acoustic pressure waves, thereby vibration and strong noise will appear in heat exchanger.

\section{Problem Definition \& Objective}

Flow-induced vibration analysis of a shell and tube heat 
exchanger is an integral element of its thermal design. A proper design is one that is absolutely safe against failure of tubes due to flow induced vibration. Most sophisticated thermal design software packages carry out vibration analysis as a routine ingredient of thermal design. This is essential since it is during thermal design that the geometry of a heat exchanger is finalized and it is this same geometry, along with flow, physical and property parameters, determines whether the given heat exchanger is safe against failure of tubes due to flow-induced vibrations. Flow-induced vibration is a very complex subject and involves the interplay of several parameters, many of which are not very well established. Although many cases of failure of tubes due to flow-induced vibration has been reported in the past several years, and an understanding of the factors responsible for these failures leave much to be desired. The literature depicts several interesting studies on specific facets of the vibration problem; however, very few investigations have considered the specific problems associated with shell and tube heat exchangers.

Hence in order to provide a simple solution to above stated problem, in this work Flow-induced Vibration Analysis of a STHE is performed to optimize the design Parameter. It is found that the FVA of STHE helps in achieving optimization in design of STHE by prevention of tube failure caused due to flow induced vibration.

\section{Shell and Tube Heat Exchanger Specification}

The details of STHE are shown in Table 1.

Figure 1 shows the STHE under consideration during manufacturing phase with all parts.

Table 1. STHE Specification.

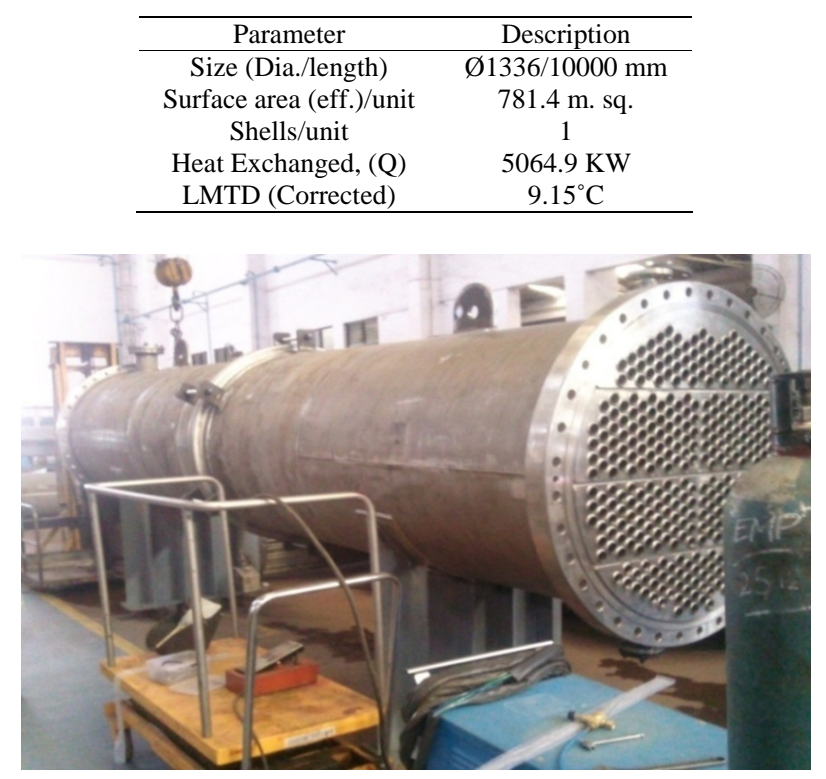

Figure 1. Shell and Tube Heat Exchanger.

\section{Flow-Induced Vibration Analysis [FVA]}

Table 2 shows the Flow-Induced Vibration Analysis Results of STHE by using HTRI software.

\section{Results \& Discussion}

From Figure 2, it is observed that the bundle shell acoustic frequency decreases from inlet to exit, hence the nature of the plot is parabolic. Acoustic resonance is due to gas column oscillation and is excited by phased vortex shedding. The oscillation creates an acoustic vibration of a standing wave type. The generated sound wave will not affect the tube bundle unless the acoustic resonant frequency approaches the tube natural frequency, although the heat exchanger shell and the attached piping may vibrate, accompanied with loud noise. Then the acoustic resonant frequency approaches the tube natural frequency, any tendency toward tube vibration will be accentuated with possible tube failure.

There are several means available to correct a resonant condition, but most could have some effect on exchanger performance. The simplest method is to install deresonating baffle(s) in the exchanger bundle to break the wave(s) at or near the antinode (This can be done without significantly affecting the shell side flow pattern. In shell and tube exchangers, the standing wave forms are limited to the first or the second mode. Failure to check both modes can result in acoustic resonance, even with deresonating baffles.

From Figure 3, it is observed that the tube natural frequency almost remains constant from inlet to center and then drastically decreases as it approaches to exit. From analysis it is observed that the individual unsupported span natural frequency is affected by tube elastic and inertial properties, tube geometry, span shape, the type of support at each end of the unsupported span and axial loading on the tube unsupported span. Most heat exchangers have multiple baffle supports and varied individual unsupported spans. Calculation of the natural frequency of the heat exchanger tube is an essential step in estimating its potential for flow induced vibration failure. The current state-of-the-art flow induced vibration correlations are not sophisticated enough to warrant treating the multi-span tube vibration problem (or mode shapes other than the fundamental) in one comprehensive analysis. Therefore, the potential for vibration is evaluated for each individual unsupported span, with the velocity and natural frequency considered being that of the unsupported span under examination.

One of the most important and least predictable parameters of flow induced vibration is fluid velocity. To calculate the local fluid velocity at a particular point in the heat exchanger is a difficult task. Various amounts of 
Table 2. Flow-induced vibration analysis of STHE.

\begin{tabular}{|c|c|c|c|c|}
\hline HTRI & ibration Analysis & \multicolumn{3}{|c|}{$\begin{array}{r}\text { Page } 1 \\
\text { Released to the following HTRI Member Company: } \\
\text { Alfa Laval } \\
\text { Alfa Laval }\end{array}$} \\
\hline Xist Ver. $6.00 \quad 3 / 31 / 2011 \quad 13: 34$ & SN: 1500214335 & & & MKH Units \\
\hline \multicolumn{5}{|c|}{ Rating-Horizontal Multipass Flow TEMA BEM Shell with NTIW-Segmental Baffles } \\
\hline Shellside condition & & Sens. Gas & (Level 2.3) & \\
\hline Axial stress loading & $\left(\mathrm{kg} / \mathrm{mm}^{2}\right)$ & 0.000 & Added mass factor & 1.394 \\
\hline Beta & & 2.717 & & \\
\hline \multicolumn{2}{|l|}{ Position in the Bundle } & Inlet & Center & Outlet \\
\hline Length for natural frequency & $(\mathrm{mm})$ & 500. & 390. & 624. \\
\hline Length/TEMA maximum span & $(--)$ & 0.328 & 0.256 & 0.409 \\
\hline Number of spans & $(--)$ & 13 & 13 & 13 \\
\hline Tube natural frequency & $(\mathrm{Hz})$ & 289.5 & 289.0 & $197.4+$ \\
\hline Shell acoustic frequency & $(\mathrm{Hz})$ & 339.9 & 310.4 & $300.4+$ \\
\hline \multicolumn{2}{|l|}{ Flow Velocities } & Inlet & Center & Outlet \\
\hline Window parallel velocity & $(\mathrm{m} / \mathrm{s})$ & 4.19 & 3.50 & 3.28 \\
\hline Bundle crossflow velocity & $(\mathrm{m} / \mathrm{s})$ & 2.33 & 2.53 & 1.46 \\
\hline Bundle/shell velocity & $(\mathrm{m} / \mathrm{s})$ & 1.85 & 2.00 & 1.16 \\
\hline \multicolumn{2}{|l|}{ Fluidelastic instability Check } & Inlet & Center & Outlet \\
\hline Log decrement & HTRI & 0.029 & 0.032 & 0.026 \\
\hline Critical velocity & $(\mathrm{m} / \mathrm{s})$ & 23.46 & 37.53 & 12.66 \\
\hline Baffle tip cross velocity ratio & $(--)$ & 0.1061 & 0.0719 & 0.1234 \\
\hline Average crossflow velocity ratio & $(--)$ & 0.994 & 0.0673 & 0.1155 \\
\hline \multicolumn{2}{|l|}{ Acoustic Vibration Check } & Inlet & Center & Outlet \\
\hline Vortex shedding ratio & $(--)$ & 0.164 & 0.178 & 0.103 \\
\hline Chen number & $(--)$ & 8851 & 12941 & 8335 \\
\hline Turbulent buffeting ratio & $(--)$ & 0.108 & 0.117 & 0.068 \\
\hline \multicolumn{2}{|l|}{ Tube Vibration Check } & Inlet & Center & Outlet \\
\hline Vortex shedding ratio & $(--)$ & 2.219 & 0.238 & 0.138 \\
\hline Parallel flow amplitude & $(\mathrm{mm})$ & 0.000 & 0.001 & 0.000 \\
\hline Crossflow amplitude & $(\mathrm{mm})$ & 0.002 & 0.001 & 0.002 \\
\hline Tube gap & $(\mathrm{mm})$ & 6.350 & 6.350 & 6.350 \\
\hline Crossflow RHO-V-SQ & $\mathrm{g} / \mathrm{m}-\mathrm{s} 2)$ & 208.80 & 293.72 & 105.02 \\
\hline \multicolumn{5}{|c|}{ Bundle Entrance/Exit } \\
\hline Fluidelastic instability ratio & & $(--)$ & 0.154 & 0.143 \\
\hline Vortex shedding ratio & & $(--)$ & 0.339 & 0.170 \\
\hline Crossflow amplitude & & $(\mathrm{mm})$ & 0.00544 & 0.00386 \\
\hline Crossflow velocity & & $(\mathrm{m} / \mathrm{s})$ & 3.61 & 1.81 \\
\hline Tubesheet to inlet/outlet support & & $(\mathrm{mm})$ & None & None \\
\hline
\end{tabular}

fluid bypass the clearances between baffles and shell, or tube and baffle tube holes. Until methods are developed to accurately calculate local fluid velocities, the designer may use average cross flow velocities based on available empirical methods.

Figure 4 shows that the bundle cross flow velocity increases from inlet to center and then drastically decreases as it approaches to exit. It is seen that the cross flow velocity in the bundle varies from span to span, from row to row within a span, and from tube to tube within a row. The reference cross flow velocity is calculated for each region of interest and is based on the average velocity across a representative tube row in that region. The presence of pass partition lanes aligned in the cross flow direction, clearance between the bundle and the shell, tube-to-baffle hole annular clearances, etc. reduce the net flow rate of the shell side fluid in cross flow. This should be considered in computing the reference cross flow velocity.

From Figure 5 it is seen that the cross flow velocity constantly increases from inlet to center and then constantly decreases as it approaches to exit.

From Figure 6 it is seen the log decrement constantly increases from inlet to centre and then constantly decreases as it approaches to exit.

Figure 7 indicate that the vortex shedding ratio constantly increases from inlet to center and then gradually decreases as it approaches to exit. 


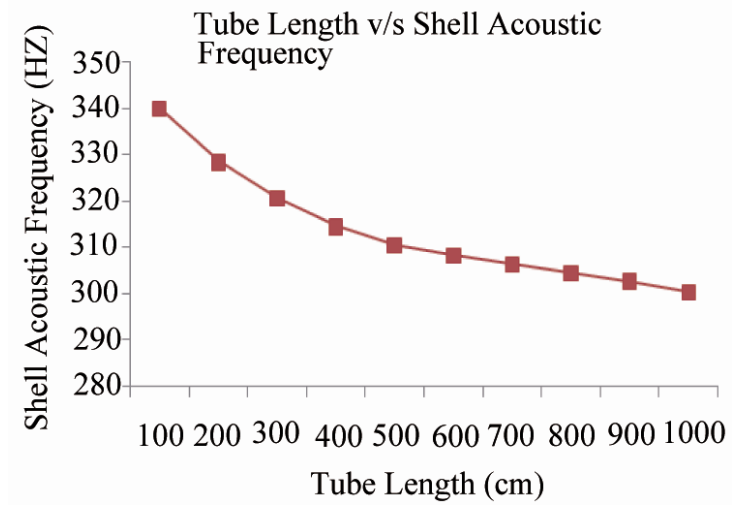

Figure 2. Tube length v/s Shell acoustic frequency.

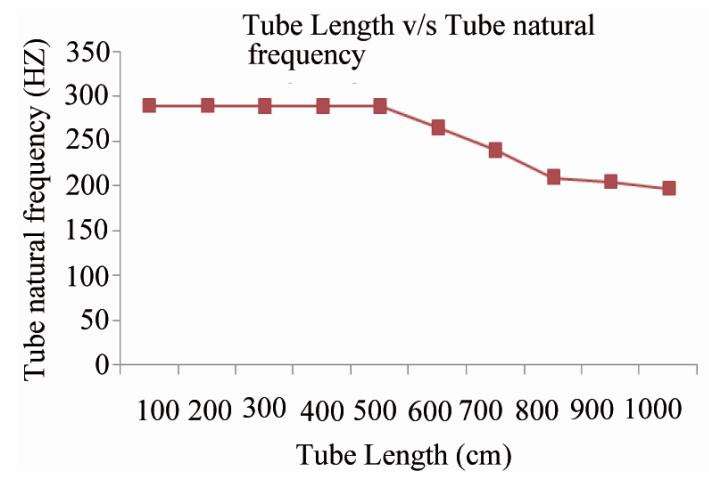

Figure 3. Tube length v/s Tube natural frequency

Tube length $\mathrm{v} / \mathrm{s}$ Bundle cross flow velocity

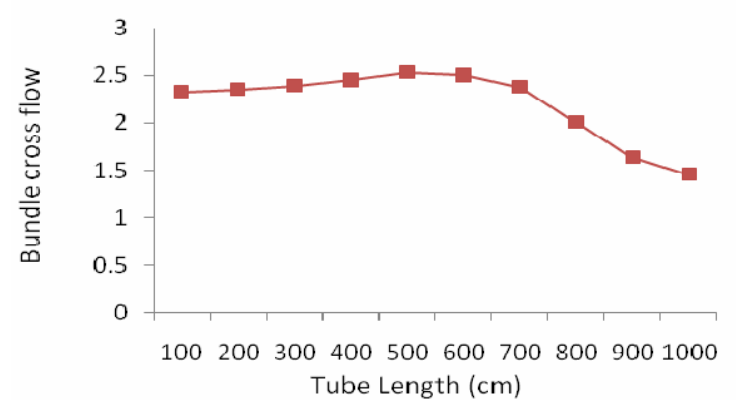

Figure 4. Tube length v/s Bundle cross flow velocity.

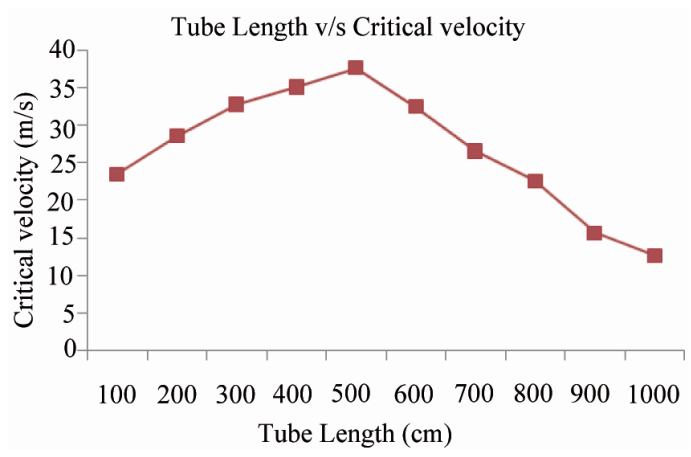

Figure 5. Tube length v/s Critical velocity.

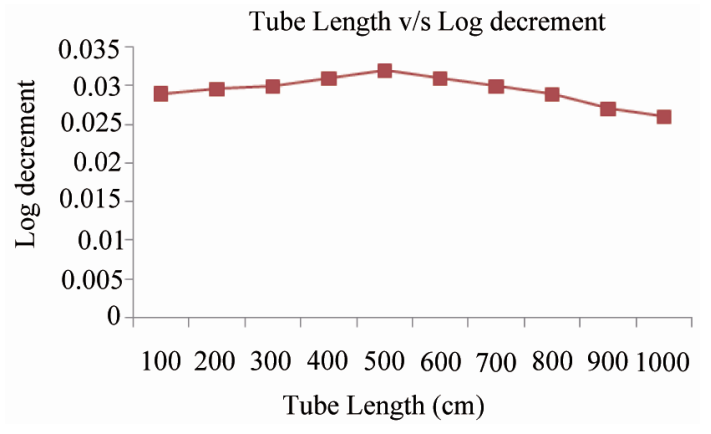

Figure 6. Tube length v/s Log decrement.

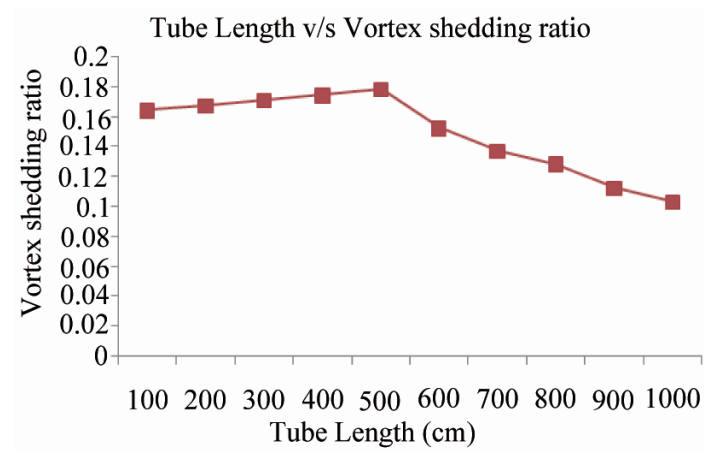

Figure 7. Tube length v/s Vortex shedding ratio.

\section{Conclusions}

From the vibration analysis of STHE it is found that the tube length has major impact on shell acoustic frequency, the tube natural frequency, bundle cross flow, critical velocity, vortex shedding ratio. From Table 2 and Figure 3 to Figure 7, it can be concluded that up to mid span of the tube (i.e. $500 \mathrm{~cm}$ ) the tube natural frequency, bundle cross flow, critical velocity, and vortex shedding ratio are gradually increasing $\&$ then decreases up to the end of tube length. Also, the mechanisms of flow-induced vibration are studied and the several main mechanisms are introduced. We finally come to the conclusion that the main parameter which largely affects the vibrations caused due to flow are dependent on unsupported tube length and varies at various locations across the tube length as unsupported tube length varies. The various other parameters which affect the flow induced vibration are critical velocity, natural frequency of tubes, crossflow velocity and acoustic frequency.

\section{References}

[1] H. Hiromitsu, M. Kouichi, N. Eiichi and F. Tohru, "Vortex Shedding from Tube Banks with Closely Mounted Serrated Fin," Journal of Environmentand Engineering, Vol. 6, No. 1, 2011, pp. 69-80. doi:10.1299/jee.6.69

[2] C. W. M. van der Geld and J. M. W. M. Schoonen, "Design Improvement of Shell and Tube Heat Exchanger 
based on Practical Experience and Numerical Analysis,” Design Report, Eindhoven University of Technology, Netherlands, 1991, pp. 74-87.

[3] S. Wang, J. Wen and Y. Li, “An Experimental Investigation of Heat Transfer Enhancement for a Shell-and-Tube Heat Exchanger," Applied Thermal Engineering, Vol. 29 No. 11-12, 2009, pp. 2433-2438. doi:10.1016/j.applthermaleng.2008.12.008

[4] V. K. Patel and R.V. Rao, "Design Optimization of Shelland-Tube Heat Exchanger Using Particle Swarm Optimization Technique,” Applied Thermal Engineering, Vol. 30, No. 11-12, 2001, pp. 1417-1425. doi:10.1016/j.applthermaleng.2010.03.001

[5] A. L. H. Costa and E. M. Queiroz, "Design Optimization of Shell and Tube Heat Exchangers," Applied Thermal Engineering, Vol. 28, No. 14-15, 2008, pp. 1798-1805. doi:10.1016/j.applthermaleng.2007.11.009

[6] R. Hosseini, A. Hosseini-Ghaffar and M. Soltani, "Experimental Determination of Shell Side Heat Transfer Coefficient and Pressure Drop for an Oil Cooler Shell-
and-Tube Heat Exchanger with Three Different Tube Bundles,” Applied Thermal Engineering, Vol. 27, No. 5-6, 2007, pp. 1001-1008.

doi:10.1016/j.applthermaleng.2006.07.023

[7] V. Hejazi, M. A. Akhavan-Behabadi and A. Afshari, "Experimental Investigation of Twisted Tape Inserts Performance on Condensation Heat Transfer Enhancement and Pressure Drop," International Communications in Heat and Mass Transfer, Vol. 37, No. 9, 2010, pp. 13761387. doi:10.1016/j.icheatmasstransfer.2010.07.021

[8] I. Conté and X. F. Peng, "Numerical and Experimental Investigations of Heat Transfer Performance of Rectangular Coil Heat Exchangers,” Applied Thermal Engineering, Vol. 29, No. 8-9, 2009, pp. 1799-1808. doi:10.1016/j.applthermaleng.2008.08.013

[9] Y. Li, X. Jiang, X. Huang, J. Jia and J. Tong, “Optimization of High-Pressure Shell-and-Tube Heat Exchanger for Syngas Cooling in an IGCC," International Journal of Heat and Mass Transfer, Vol. 53, No. 21-22, 2010, pp. 4543-4551. doi:10.1016/j.ijheatmasstransfer.2010.04.038 